Original Research

\title{
Dementia: Aloneness, Social and Relational Engagement, and Psychological Growth in Families
}

\author{
Bruce Walmsley $^{1,}{ }^{*}$, Lynne McCormack ${ }^{2}$
}

1. University of New South Wales, School of Public Health and Community Medicine, Sydney NSW 2052 Australia; E-Mail: bruce.walmsley@unsw.edu.au

2. University of Newcastle, School of Psychology, Faculty of Science, Callaghan NSW 2308, Australia; E-Mail: Lynne.McCormack@newcastle.edu.au

* Correspondence: Bruce Walmsley; E-Mail: bruce.walmsley@unsw.edu.au

Academic Editor: Lisa Hollis-Sawyer

Special Issue: Got Aging? Examining Later-life Development from a Positive Aging Perspective

OBM Geriatrics

2018, volume 2 , issue 4

doi:10.21926/obm.geriatr.1804013
Received: June 23, 2018

Accepted: September 29, 2018

Published: October 08, 2018

\begin{abstract}
Background: Minimal research investigates negative and positive perspectives of wellbeing in families, when a member with dementia is limited in their speech, or speech is absent.

Methods: Seeking to explore this phenomenon further, semi-structured interviews sought negative and positive subjective interpretations from 27 family carers (mild to profound dementia). Interviews explored the participants' experience of changing relational and social engagement when a family member lives with dementia. Data were analysed using the protocols of Interpretive Phenomenological Analysis.
\end{abstract}

Results: One superordinate theme, Lost and found, described family carers struggle to make sense of ambiguous and inconsistent social engagement in a member with dementia. It overarched three sub-themes: Aloneness; Engagement and Psychological growth. First, these participants describe a growing sense of isolation that accompanied unexpected societal stigma towards themselves and their family member with dementia, and consequential feelings of shame. Second, seeking solace in their family group, carers rediscovered opportunities for more intimate engagement rooted in familial bonds,

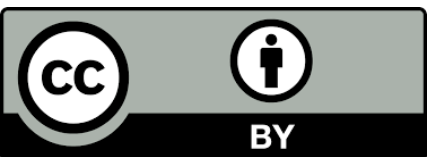

(C) 2018 by the author. This is an open access article distributed under the conditions of the Creative Commons by Attribution License, which permits unrestricted use, distribution, and reproduction in any medium or format, provided the original work is correctly cited. 
familiarity and trust. Third, in response to their experiences of aloneness and stigma associated with dementia, personal integrity became the conduit for psychological growth where 'self' was able to nurture hope, acceptance, meaning and advocacy.

Conclusions: Family carers' acceptance of a need to be more adaptive brought positive redefinitions of self and relationships within the family group. As a result, Relational Social Engagement (RSE) during family interactions was something to be enjoyed despite the distress of loss and uncertainty. These findings can inform health professional support.

\section{Keywords}

Dementia; family; Interpretive Phenomenological Analysis; psychological growth; relational social engagement

\section{Introduction}

When a family member with dementia is physically present but their relational and social connection appears to fluctuate or disappear, it is distressing and a potentially traumatic experience for family carers [1-4]. Described by family carers as an experience of "missing the person" [5], it may be that their empathic and emotional support for that person leads them to oscillate between seeking to rescue yet wanting emotional distance. Such helplessness is explained through Systemic Trauma Theory, in which intimate and extended contact with others in traumatic distress leads to vicarious effects [6]. Indeed, in moments of helplessness, families may regard the member with dementia as "totally gone" [1], especially when that person's awareness and speech fluctuates $[3,4]$. However, when family carers are able to embrace alternate communication pathways (e.g., touch, dance and walking together), they are able to relationally reconnect "what was with what could be" [3]. However, this study is interested in the interface of family and the medical model of care and its impact on family wellbeing once verbal communication is minimal or has ceased in the family member with dementia. We are seeking both positive and negative interpretations of these experiences, a recent area of research.

Communication, connection, relationship, belonging and self-expression have been described as inherent human needs [7]. Indeed, people are regarded as social beings who retain their sense of self through interpersonal stories, actions and responses [8-10]. Yet when communication pathways change in families living with the impact of dementia, it may be that family carers experience loss of identity, connection and belonging. Indeed, family carers describe embarrassment when a member with dementia interacts in confusing and unusual ways $[3,5,11]$ and when family carers struggle to explain decisions or reassure, strain gives way to anger as repetitive questions become overwhelming $[12,13]$.

From the perspectives of those who live with dementia, changing communication pathways are equally challenging, when for example speaking becomes an experience of searching "for a word and I can see it walking away from me. It gets littler and littler. It always comes back, but at the wrong time. You can't be spontaneous" [14]. Similarly, people with dementia describe a conversational shift away from reasoning towards emotion, as "the locus of my attention is definitely shifting from my head to my heart. ... at all times, I am aware of my feelings [15-17]. 
As such, families living with the impact of dementia are encouraged to be creative and willing to recognise, interpret and respond to alternative patterns of communication $[7,18,19]$. Indeed, it is recommended that family carers adopt an 'intentional stance' by interacting in the belief that the person with dementia is also intending to communicate [20]. This is especially important in families when a member has limited or absent speech due to dementia. In such families, when family carers treat the interactions of the member with dementia as understandable, the intimacy of reciprocal interactions can stimulate thoughts, emotions and expressiveness in the person with dementia $[18,19]$. For example, interactive family visits to an in-care member with dementia, indicate that awareness levels can be greater than previously recognised within the care home environment $[18,19]$. Such optimal engagement would appear to be underpinned by 'distinctive familial bonds' and belonging in which the family, inclusive of the member with dementia, could spontaneously express differences and enjoy commonality [19].

However, such intimate connection can "only be done by a person who is secure enough ... not [to] get lost in what may turn out to be the strange or bizarre world of the other, and can comfortably return to his own world when he wishes" [21]. As such, for many family carers preoccupied with frustration, shame and embarrassment surrounding alternative communication pathways, it may be that they miss opportunities for powerful yet subtle ongoing connections $[2,3$, $18,19,22,23]$. When familial connections are lost, it can be a source of distress for families that is "confusing and incomprehensible" and potentially traumatic [1, 3, 4, 24].

Undeniably, traumatic responses are a possibility in the family carer, when families helplessly witness the decline of a member with dementia and battle for patient advocacy within a powerful care system seen as facilitating opposition instead of family inclusion [2-4, 25]. When that member with dementia also appears to be relationally and socially absent, family carers describe a "traumatic" and "ambiguous loss" [1, 2]. Yet it may be that such adversity can be a catalyst for positive change. The positive psychology literature indicates that adversity, and subsequent efforts to make sense of adversities, promotes a normal search for personal meaning, purpose and direction in life $[26,27]$. However, both positive and negative assessment of any adversity must be acknowledged for adaptive coping to occur [26, 28-32] and such positive adaptation occurs when a supportive social environment encourages agency and meaningful relationships [26, 29, 33].

Yet in the context of dementia care, this remains a new area of research. Although, it has long been understood that family carers experience negative and positive outcomes [34-36], the coexisting relationship between those outcomes has only recently been explored [2, 19]. Therefore, this study seeks to understand the negative and positive perspectives of wellbeing in families, when a member with dementia has limited or absent speech. It is particularly interested in the relationship between these negative and positive subjective interpretations, across the dementia trajectory for all generations involved in care.

\section{Methods}

\subsection{Participants}

Twenty-seven family carers (in 17 family groups across five care homes) who were experiencing the mild to profound stages of dementia, volunteered for this study (demographics: Table 1). This 
study was approved by the university human research ethics committee. Pseudonyms have been used.

Table 1 Family groups at the time of data gathering

\begin{tabular}{|c|c|c|c|}
\hline Family & Resident, age (years) & Visitor/s, age (years), relationship & Caregiving (years) \\
\hline \multicolumn{4}{|l|}{ Mild } \\
\hline 1 & Jessie, 73 & $\begin{array}{l}\text { Kym, 52, Daughter } \\
\text { Craig, 56, Son-in-law }\end{array}$ & 12 \\
\hline 2 & Jack, 96 & $\begin{array}{l}\text { Linda, } 67, \text { Daughter } \\
\text { Stephen, 52, Son }\end{array}$ & 3 \\
\hline 3 & Frank, 82 & Danielle, 42, Daughter & 10 \\
\hline 4 & Rose, 83 & Gail, 55, Daughter & 6 \\
\hline \multicolumn{4}{|c|}{ Moderate } \\
\hline 1 & Phyllis, 80 & Bob, 80, Husband & 7 \\
\hline 2 & Alice, 84 & Pat, 61, Daughter & 7 \\
\hline 3 & Ruth, 76 & $\begin{array}{l}\text { Lori, 51, Daughter } \\
\text { Kaye, 49, Daughter }\end{array}$ & 7 \\
\hline 4 & David, 76 & Julie, 65, Wife & 9 \\
\hline 5 & Edith, 93 & $\begin{array}{l}\text { Janet, 54, Daughter } \\
\text { Becky, 23, Grand-daughter }\end{array}$ & 4 \\
\hline \multicolumn{4}{|l|}{ Severe } \\
\hline 1 & Harry, 84 & Joy, 80, Wife & 4 \\
\hline 2 & Pam, 74 & $\begin{array}{l}\text { Doug, 77, Husband } \\
\text { Tracey, 51, Daughter }\end{array}$ & 6 \\
\hline 3 & Ross, 72 & $\begin{array}{l}\text { Dawn, 71, Wife } \\
\text { Lisa, 48, Daughter } \\
\text { Cathy , 57, Daughter }\end{array}$ & 4 \\
\hline 4 & Esther, 80 & $\begin{array}{l}\text { Diane, 53, Daughter } \\
\text { Megan, 27, Grand-daughter } \\
\text { Kayla, 26, Grand-daughter }\end{array}$ & 5 \\
\hline 5 & Ron, 84 & Betty, 76, Wife & 5 \\
\hline 6 & Don, 70 & Joan, 70, Wife & 4 \\
\hline \multicolumn{4}{|c|}{ Profound } \\
\hline 1 & Helen, 96 & $\begin{array}{l}\text { Gary, } 72 \text {, Son } \\
\text { Susan, 64, Daughter-in-law }\end{array}$ & 10 \\
\hline 2 & Deborah, 69 & Richard, 72, Husband & 10 \\
\hline
\end{tabular}

\subsection{Epistemology}

From a phenomenological and interpretative hermeneutical approach, this study offers a platform for exploring a complex topic through critical reflection of a real world where unobservable realities exist. Aligned with critical realism, this study interprets how participants 
socially construct, interpret and understand the world. Within a critical realistic paradigm, access to the world is always mediated. As such, individuals engage in 'hermeneutic enquiry' by continuously interpreting to make sense of their world [37]. This fits comfortably with symbolic interactionism, whereby: (a) people act towards things based on the meaning those things hold for them; (b) meaning is derived from social interaction; and (c) meaning is variable, uncertain and modified by interpretation $[38,39]$.

\subsection{Procedure}

Following university ethics approval, care managers invited family members to participate in the study. Criterion for inclusion was an in-care family member with mild to profound dementia, as assessed by the care home managers using the Clinical Dementia Rating Scale (CDR: [40]). The CDR estimates capacity across a number of cognitive and functional domains to provide a symptom level from none to severe, profound and terminal [40].

Details of the study were provided to participants, and written consent gained. The first author collected demographic information and completed the interviews at the participating facilities at a time convenient to all. Questioning tapered down to the topic of interest [41] encompassing participants' thoughts, feelings, priorities, world view, communication, human dynamics, spirituality and future life. The researcher and participants engaged flexibly in the double hermeneutics of the interview. Participants engaged willingly with few prompts. Each hour-long individual/group interview was digitally recorded to establish the data set for the study.

\subsection{Analysis}

Using a recommended protocol for Interpretive Phenomenological Analysis (IPA: [41]; Table 2), the data set was analysed independently by the authors, providing in-depth specific interactions, statements and themes in the search for all possible meanings [42-44]. This was followed by collaborative and robust discussion where bracketing of biases identified individual risk to interpretation in line with the methodological steps and the philosophical roots of IPA which recognises the importance of both individual experience and the constructed nature of human experiences such as dementia [45-47]. Although specific interpretation of interactions, statements and themes sought to recognise all possible meanings [43], the authors remained alert to the risk of unconscious analytical biases of causality and directionality in the IPA process [48]. During both individual and joint analysis, the authors were conscious to bracket their biases through a 'double hermeneutic process' of bringing meaning to the participants' efforts to make sense of their own experience $[37,49,50]$.

\subsection{Credibility}

The first author conducted the digitally-recorded interviews. Both authors then independently analysed the data, before meeting to discuss and debate their independent interpretations until both authors arrived at agreed themes. Agreed themes were evident when clear support was found in rich data extracts [51-53]. Unlike quantitative research, causal evidence and inter-rater reliability were not sought. Instead, independent auditing sought one account of the data that achieved internal coherence and presentation of evidence. This was supported by an audit trail 
comprising audio-recordings, transcripts, theme development, notes, diagrams and thematic definitions [51-53].

Table 2 Analytical process for IPA for interviews [42, 44, 48]

\begin{tabular}{ll}
\hline Stage & Process \\
\hline 1 & Bracket personal biases and preconceptions that could influence interpretation \\
of the data. \\
Establish an audit-trail of the data, so that interpretations can be traced from \\
initial themes to the final thematic narrative. \\
Line-by-line reading of the data to select experiential claims, concerns and \\
understandings of individual participants. \\
Identification of the emergent thematic patterns, noting convergence and \\
divergence. \\
Cross-referencing of emergent themes with psychological and theoretical \\
knowledge and analysis of 'positionality', 'roles and relationships', \\
'organisations and systems', 'stories', 'language and its context' to interpret \\
participant meaning. \\
Generating an illustrative structural-map of themes. \\
Completing an independent audit of the data with consensus reached through \\
robust debate. \\
Engaging in an iterative and inductive cycle of continually returning to the data \\
and revising interpretation. \\
Developing a narrative, with vivid extracts grounded in the data, to take the \\
reader through a convincing interpretation theme-by-theme.
\end{tabular}

\section{Results}

Across the mild to profound stages of dementia, 27 participants volunteered for this study. One superordinate theme, Lost and found, describes family members oscillating between negative and positive change, as they struggled to make sense of ambiguous social awareness and engagement in a family member with dementia. Lost and found overarched three sub-themes: (1) Aloneness, (2) Engagement and (3) Psychological growth. Within these sub-themes, first, these participants describe a growing sense of isolation that accompanied unexpected societal stigma towards themselves and their family member with dementia, and consequential feelings of shame. Second, seeking solace in their family group, carers rediscover opportunities for more intimate engagement rooted in familial bonds, familiarity and trust. Third, in response to their experiences of aloneness and stigma associated with dementia, personal integrity became the conduit for psychological growth where 'self' was able to nurture hope, acceptance, meaning and advocacy. Family carers' acceptance of a need to be more adaptive brought positive redefinitions of 'self' in relation to 'other' within the family group. As a result, Relational Social Engagement (RSE) during family interactions was something to be enjoyed despite the inevitable distress of loss and uncertainty. As a result, adaptive wellbeing emerged to co-exist with appropriate distress in these participants. Table 3. (Notations: Appendix 1). 
Table 3 Superordinate theme, Lost and found, overarching sub-themes

Aloneness: stigma and shame that isolated those with dementia and families by association.

- Isolation: isolated at home, family members with dementia sought security rather than the public embarrassment of declining social skills.

- $\quad$ Alienation: finding it hard to belong, family members with dementia diverted social attention from their forgetfulness.

- Abandonment: frustration and depressing feelings of loneliness in family carers, when family/friends stopped contact and unsupportive friendships were let go.

Engagement: underscored by familial bonds, trust and familiarity, family carers examined opportunities for intimacy and engagement within their family group.

- Familial retrospective: for family carers, negative and positive appraisal of intrafamilial memories came to explain present-day familial bonds.

- Familial security: situated in the connectedness, trust and familiarity of the family group, unmistakable identity and social skills re-emerged in those with dementia.

Growth: rejecting stigma and refusing shame, distressing losses nurtured family carers' search for self-integrity and hope, to positively redefine self and familial relationships.

- Acceptance: co-existing with distress, family carers reached acceptance of unpredictable, fluctuating, and irreversible social change.

- Meaning: bringing positive meaning to their experiences, family carers accumulated wisdom for more flexible coping with developments.

- Voice of advocacy: wisdom gained through experiences so far, motivated family carers to give an empathic voice of support for other individuals and families experiencing dementia.

\subsection{Aloneness}

Underpinned by what appears to be community fears and misconceptions, stigma and shame isolate those with dementia and their family carers by association. As a result, the family carers within this chapter experience frustration, embarrassment, and in extreme circumstances depressing loneliness. In turn, they witness a family member with dementia seeking the security of home or striving to fit in socially through whatever means possible.

3.1.1 Isolation. Isolation describes family members living with dementia becoming isolated in their homes, when it would seem that their changing social skills and subsequent reactions in others threaten their sense of security. This brings embarrassment to them and frustration to their family members.

Rather than risk further social embarrassment, mothers with dementia isolate themselves from their local community:

She just didn't want to talk ... She'd be quite angry ... She didn't go out of the house ... hadn't had her hair cut for two years ... wouldn't go to the doctor (Gail).

Even in far-off communities, unlikely to be visited again, a husband with dementia choose security in isolation rather than risk social shame: 
We were travelling around Australia ... he used to be the most social person ... then he started not wanting to go out ... not joining in. By the time we got back home that was really pretty evident (Julie).

For mothers with dementia, crankiness becomes a way to distance inquisitive daughters. These daughters find no clear turning point when negativity started to redefine familiar motherdaughter bonds:

It changed from the very beginning ... for me, crankiness and agitation because she was just not there? Or losing it? Or it was just like frustration? ... She was cranky ... I was cranky. ... I've always wanted to spend time with Mum ... It was real sort of change... At the time, I didn't know when it actually changed (Kaye).

Rather than feel overwhelmed by losses in awareness, self-withdrawal in mothers gives way to obsessional behaviour:

She was always sorting things... It was her way of staying in control (Kym).

3.1.2 Alienated. Still wanting to belong socially but finding it increasingly difficult, family members with dementia seek to divert social attention from their forgetfulness. For example, mothers/grand-mothers with dementia are seen to divert attention from such insecurities by striving to keep up social appearances e.g., "They might think I'm weird? I'm a dumb bat". When that person perceives that their sense of self-competence is being challenged, internalised shame gives way to anger and is witnessed by daughters/granddaughters such as Jan and Lilly:

She knows she hasn't got a good memory, so she's trying to make up for that by trying to come across as well kept ... (Lilly). That partly comes from Dad who used to say "Don't be such a Dill Weed, Edith." ... She'd think, "Oh, yes, I suppose I am" .... She'd take it. ... It's embedded in her memory. If she thinks she looks foolish [now], she's more likely to get angry (Jan). Yes, hostile (Lilly).

Such insecurities are seen to resurface in a mother with dementia, when older siblings visit:

I think she's always felt because they were more academic ... she wants approval. I think it's been lying dormant for some years. ... Usually she wears a big hat (Lucy).

Mothers, recognised by daughters as just wanting "to belong" despite having "lost her social skills" are seen to disregard social norms. The symbolic meaning behind their creative responses to perceived alienation is understood by observant daughters:

Mum undid the buttons on her cardigan ... She looked at her, and said "You didn't notice that I undid the buttons on my cardigan." That was her way of saying "You've left me out of the conversation" (Lucy).

3.1.3 Abandonment. In extreme conditions, when unsupportive friendships are let go, or family and friends stop phoning or visiting, frustration and depressing feelings of loneliness overwhelm family carers. For instance, observing the minimisation of a wife with dementia, a husband decides to end friendships that he now believes are insincere:

"She did this." "She did that." I decided that I didn't have to put her through that ... I was hurt more so for Marilyn ... [They] were like shadows - false people (Bob).

Disappointed and frustrated, daughters see family friends place their emotional discomfort ahead of a father's sense of support:

Some people don't know what to say ... and they feel like they're going to cry. Well we all cry! At least he knows that they are there and that they care (Lisa). 
When family and friends stop calling and visiting, depressing feelings of being alone emerge in the wives in this chapter. Spilling over to bitterness, wives struggle to make sense of social avoidance that envelopes a husband with dementia and extends to them as wife:

It's a very lonely feeling ... when ... people that used to come ... don't want to become involved. I feel very hurt ... cynical ... disappointed ... [less] patience with people. ... I'm starting to think maybe they're concerned that this might happen to them (Joan).

Inevitably drawn towards loss, daughters seeking familiar relational bonds find ambiguity and cruel disappointment:

Is she just 'yes-ing' and 'no-ing'? ... It's unfair. She's alive ... and we want her ... but it's like we can't have her (Kaye).

For some husbands, efforts to move past loss and distress give way to feelings of loneliness:

Even though I have immersed myself into the activities of the U3A [University of the Third Age] in a bid to move on, I know that most of these activities are those that Pam would also have enjoyed ... but I am doing them alone (Doug).

For some wives, depressing feelings of being alone give way to overwhelming panic and despair:

Depression has taken over my life ... I can understand, let me tell you, how people take their own lives ... panic attacks ... you're in this damned big dark black-hole ... you think you're never going to get out of it (Betty).

\subsection{Engagement}

Underscored by familial bonds, trust, and familiarity, family carers begin to redefine opportunities for intimacy and engagement within their family group. Appearing to turn inwards upon the family group, participants find what appears to be security within the family group and patterns of engagement rooted in familial bonds.

3.2.1 Familial retrospective. For these family carers, negative and positive appraisal of historical interpersonal experiences with their family member with dementia, come to explain present-day familial bonds with that person. For example, daughters describe negative bonds reflecting poor maternal attachment. Unable to resolve past maternal rejection, daughters choose to replace their regressive views with maturity, compassion, and forgiveness:

I don't think Mum accepted me and I don't think I accepted her. ... I found it frustrating and annoying that I was put in that position when she hadn't been there for me, which is probably an infantile way of looking at it ... So I had to separate ... that sort of resentment ... and try and leave that behind (Kym).

Living in the moment, past differences between mother- and daughter-in-law give way to positive relational change. Familiarity promotes security:

We didn't get on well ... but when she came here and into care .... I was a familiar face who would talk to her and take her to things ... suddenly I was her very best friend (Susan).

When dementia disregards past maternal defensiveness, daughters experience long-awaited maternal recognition:

She's always had her defence up, never let anyone in ... now that's not there as much. ... I'll walk in with ... my grandkids and she'll be delighted to see them, whereas ... she was never delighted to see my kids. I think "At last!" (Kym) 
Noted by a visiting wife, distinctive familial bonds of "devotion" disregard ambiguous interpersonal losses, even in severe stages of dementia:

He said to me today "You're lovely. You're really good and I love you" and I said "Well how about a kiss" So he gives me a kiss .... I don't think he would give anybody else a kiss. He was so it's hard to say this - he was so devoted (Joy).

3.2.2 Familial security. Situated within the connectedness, trust, and familiarity of the family group, family carers witness unmistakable identity, and social skills momentarily re-emerge in a relative with dementia. Witnessed relaxation in that person gives way to noticeably greater interpersonal awareness and engagement:

I think it's her mood ... if she's feeling good ... she will be more aware of things ... Make her more relaxed ... casual (Lilly). It depends on her mood (Jan).

Sisters describe the re-emergence of their "old Mum":

It was humour. I was thinking "Wow! That's old times. That's the old Mum" (Kaye). It really depends on the day, a good day or the right conversation (Lori) ... It just happens. .... something might click (Kaye).

Symbolic expressions of former roles are recognised by a visiting husband. Recognising those aspects of identity allows him to witness the continuation of meaningful engagement in a wife with dementia:

As a mother and a person who understands little children ... I think ... that she's sort of still got those inbuilt knowledge and skills ... buried pretty deep (Richard).

Familiarity is seen by supporting family members as a conduit for social engagement, as was distinctiveness: Recognition is seen to make an increasingly uncertain world more certain for family members with dementia:

Your voice, a thought, something you're wearing, a ring, something she looks at ... she recognises (Jan). She always reacted to our voices, always. I think she always knew that we were positive (Susan).

Discussing patterns of engagement, family members muse at the interpersonal awareness and engagement retained by a family member with dementia. Some participants believe that family members with dementia are unaware of historical relational bonds within their family:

She often doesn't know why she knows me, or who I am ... she just knows that she knows me (Jan). When she lost the ability to speak, we don't know who she thought we were, except that we do know that we're important to her (Susan).

Indeed, some participants disregard medical views that they are just familiar faces, and instead find validation of historical relational bonds through the love expressed by parents dying with dementia:

I got a beautiful smile every time I walked into my mum's. I was heartbroken to think that I'm only familiar. I just didn't believe them. ... She smiled at me at the end. All I wanted was a smile. That helped me. ... "I always thought she knew who I was" (Linda).

\subsection{Growth}

Rejecting stigma and shame that challenges both personal integrity and hope, Growth describes a redefining of self that nurtures acceptance, meaning and further change through voice 
of advocacy. For those families able to embrace the fluctuating presentation of dementia, a positive redefinition of intimacy and relational engagement emerges.

3.3.1 Acceptance. Over time, most family carers accept the unpredictable, fluctuating, and irreversible social change in a family member with dementia. Despite ongoing distress, fluctuating interpersonal awareness and engagement are seen as an inevitable part of daily developments. Acceptance makes room for more flexible coping.

When a husband rejects stigma and refuses shame, acceptance of unusual social behaviour in a wife with dementia allows him to continue daily life with less disruption:

She started to see ... reflections ... in the car ... when we were in car parks ... "Look as much as you like fellas" ... Because I'd accepted it, and that was Pam. ... "C'mon Pam let's go and do our shopping" (Doug).

Conversely, pockets of acceptance are also found in the community. Daughters describe "safe places" without judgement and the subsequent "anxiousness" and "confusion" in a mother with dementia:

I've found safe places. The Thai restaurant... [The owners] give her a hug, and they sit her down ... all the other customers in there get the picture. So it is a safe place for Mum ... without all the judgment (Lucy).

Feeling accepted by a previously unwelcoming mother, daughters let their defences go. Moving beyond self-absorption towards common ground with a mother now living with dementia, daughters recognise that acceptance has come to positively redefine relationships in general:

Now ... she has to accept me ... and I have to accept her as she is ... "Why have that conflict?" You can pretty much translate that to anyone (Kym).

Daughters note ease when they focus on present developments rather than ruminating over past regrets:

You can only go along with the waves, really, go along with the tides, and deal with what you have on the day (Tracy). It sort of makes it easier for me ... you don't get bogged down on what has happened in the past ... every day is a new day (Kym).

\subsection{Meaning}

Family carers accumulate wisdom for more flexible coping with developments when they were able to bring positive meaning to their distressing losses. For some family members, storytelling is a powerful tool for positively integrating adversity into everyday life. New meaning allows them to move forward out of adversity:

Indigenous dreamtime stories explain in a mystical way, what is the unexplainable at the time. So therefore, what I do is mainly look at those sorts of stories .... I can make stories up for myself to explain what is happening ... to give peace to myself (Lucy).

Through skilful words, daughters come to reinterpret problems as an opportunity for new perspectives that brings wisdom, acceptance, and flexible coping:

Adventure is never knowing where you are. So if I am lost in it all, it's an adventure (Lucy).

And:

The mind ... it's almost like a wind ... like a breeze. ... it sort of comes and goes (Tracy). 
Inexorably drawn towards loss and grief, daughters seek familiar maternal bonds through storybased retrospectives of a mother's life. In positively redefining a mother, daughters find that continuity in maternal bonds can co-exist with loss and ambiguity:

I needed to put it down. ... A PowerPoint of "Mum's story" ... It's like meditation. It makes me remember Mum as she was; A very viable person. ... A viable person is one that still is positively involved in a community and giving positive benefits. We still get enjoyment from Mum, so I would still call her a viable person (Lucy).

3.4.1 Voice of advocacy. Experiential wisdom gained to date motivates many family carers to give an empathic voice of support for others experiencing distressing social losses related to dementia.

Redirecting their emotional pain into advocacy, a wife considers the value of their experiences for helping others:

I dearly would love to give a talk to people that are just starting out ... to tell them my idea and what I think would help (Joy).

When wives reject stigma and refuse shame, experiential knowledge spills over to advocacy focused on 'common-sense care', social inclusion and participation:

I do believe that you have got to do more things ... get them out ... do more to stimulate their minds ... I do think that that's important (Cathy). ... A lot of common-sense comes into caring ... They shouldn't be hidden away. They should be out in the public and doing things. ... Help them, but push them that little bit further (Joy).

For some wives, humour brings their message home:

He was a bit slow, but we went bowling, dancing, playing darts. ... He wasn't throwing the dart at anybody else. He was throwing it at the board (Joy).

For a young granddaughter, a personal search for integrity and hope gives way to positive new outlooks on essential human worth. This offers hope for a generational shift in thinking about people living with dementia:

She doesn't seem like the same Granny that she used to be. She used to be a really good buddy... we'd go out for coffee ... we'd talk ... now it's really hard to hold a conversation ... I feel like that's where I got a lot of meaning from ... placed value on that instead of they're just a person ... they should be loved and ... valued, no matter what ... We're human beings, we're not human doings (Lilly).

\section{Discussion}

This study presents a new perspective highlighted by the narratives and interpretations of 27 family carers. Unique to the literature, this study sought both negative and positive subjective insights of wellbeing in families, when a member with dementia has limited or absent speech. It provides insights on meaning making brought to the psychosocial impacts of dementia on the individual family carer and family relationships, across the dementia trajectory for all generations involved in care. The themes identified in this study provided a lens into a plethora of emotional uncertainties often forced on the participants by both negative and positive change. Stigma and social isolation were unexpected co-partners on the journey however, equally unexpected was the turning towards family to seek solace in their family group, and the rediscovery of intimacy and engagement rooted in familial bonds, trust and familiarity. Distress was still evident but through 
becoming adaptive to an ever-changing path, self began to nurture hope, acceptance, meaning and advocacy allowing psychological growth to emerge.

This study indicates that, family carers experienced intrinsic drives to reduce their distress through efforts to both avoid and bring purposeful meaning to their adversities. As such, they came to redefine their responses to the ambiguous social loss of a family member with dementia, as a mix of oscillating responses, both positive and negative. Stigma and shame left families struggling to adapt to a community where they were at times avoided, yet also where "certain safe places" offered inclusion without judgement. Once able to accept this uncertain social environment i.e., that their perspective of relational intimacy and social engagement could run contrary to public fears and misconceptions, family carers more readily positioned themselves as advocates for social inclusion. As such, they began to acknowledge that psychological wellbeing and distress could co-exist alongside experiences of relational intimacy and social engagement within their family group. By embracing personal integrity and hope, rather than accepting stigma or feeling shame, these family carers began to positively redefine self and familial relationships for adaptive flexibility.

Similarly they spoke of witnessing the fear and uncertainty in their loved one who was experiencing the confusion of changing social skills and subsequent community reactions which in turn motivated efforts to avoid public embarrassment or a continuing push to belong. This highlighted the degree to which stigma was experienced by family carers and witnessed as lack of competence in the family members with dementia. This was particularly evident when a family member with dementia struggled to positively reposition themselves against stigmatising treatment and instead positioned themselves in shame or hostility.

For these family members, the findings indicate that both primary and vicarious traumatic responses were experienced when their inability to alleviate the ambiguous social loss of their family member was cumulative upon social abandonment, shame and distressing losses that compounded in quick succession. In extreme circumstances, responses to the ambiguous loss of a family member whose interpersonal awareness and social engagement fluctuated encompassing traumatic responses of incomprehension and intense distress that gave way to frustration, anger, panic and depressing feelings of loneliness and despair.

Yet despite distress, growth domains of acceptance and meaning enabled these family carers to embrace Relational Social Engagement (RSE) within their family and create further positive change as a voice of advocacy. Consistent with earlier research, RSE highlights distinctive familial bonds that offer security and comfort for those with dementia to spontaneously enjoy common ground and express differences within the family group $[18,19]$. For the supporting family members, refusal of shame, rejection of stigma, and redefining relational loss became the vanguards of hope, and relational and social intimacy as the stages of dementia progressed.

Although theories of growth posit social support as a necessary condition for growth following adversity, when social support was lacking or even antagonistic for family carers, findings of this study would suggest that seeking RSE with a family member who has dementia stimulates meaning making for psychological growth. Generating renewed moral integrity and authenticity in family carers, RSE appeared to motivate their advocacy and positive change across other domains in time.

However, finding opportunities for relational intimacy and social engagement within their family group provided an outlet for families struggling to 'connect what was with what could be'. 
In witnessing a family member unable to advocate against stigmatising views and treatment, the findings suggest that stigma and shame both undermined and motivated these family carers in their struggle for acceptance, meaning and eventual voice of advocacy. These findings indicate that ambiguous social losses bring both adjustment challenges to families and the opportunity for imbedding distressing memories in the overall narrative. Over time, those family carers who moved successfully beyond stigma and shame, were able to reconnect with a family member with dementia at a deeper, simpler level that was previously overlooked because of a preoccupation with the frustrations and devastation of losses and overemphasis on what the person could no longer do.

While growth domains were not evident in all interviews, when they were, participants describing growth were more likely to describe losses in the past tense. This suggests that for these family carers, as psychological wellbeing took hold, distress within their social experiences dominated by negative domains inevitably declined. Although there was no clear turning point between negative and positive change for participants, positive examination of self and familial relationships appeared to rely on time and finding "certain safe places" within the community. Indeed, the importance of 'dementia friendly communities' is highlighted, as they emerge to help individuals with dementia feel more confident about asking for help with less embarrassment [54, 55]. Dementia-friendly communities also offer families opportunities for meaningful community contribution through consultation on infrastructure improvements, public awareness, and improved dementia literacy within that community [54, 55].

If social support is lacking, as experienced by these families, it is a known barrier to psychological growth [56, 57]. Yet for these participants, theirs was an experience of becoming individual experts in relational intimacy, social engagement, and triggers for unexpected levels of RSE. The possibility of psychological growth in these families, highlights the need for relational models of dementia care inclusive of families, which stimulate psychological growth for individual family members.

As such, this research offers a qualitatively different perspective for relational models of care that encourage the recovery of psychological wellbeing for individual family members. The perspectives of these family carers highlight that they remain relationally and socially connected to family members with dementia, without which they might lose an important source of purpose and meaning in their overall life narrative. Further, the researchers would welcome further investigation into the construct of RSE and the opportunities to preserve and optimise retained awareness and interpersonal skills in people living with dementia. This presents the opportunity for health professionals seeking wellbeing in families to deliver dementia care inclusive of RSE during family interactions.

\subsection{Limitations and Strengths}

This study is subject to biases of memory, perception and recall that can occur during focus groups and interviews. However, the interviews did not restrict participant meaning making, whether negative or positive. Similarly, although IPA necessarily involves researcher interpretation, every attempt was made to externalise preconceptions and bring credibility to interpretation through independent auditing. Similarly, what participants experienced and how they brought 
meaning to those experiences offered a unique subjective insight into a complex and sensitive topic which cannot be generalised to the wider community without further nomothetic research.

\section{Conclusions}

This study presents an important dimension of the lived experiences of family carers in relation to their wellbeing, when a member with dementia has limited or absent speech. It provides insights across the dementia trajectory, for all generations involved in care. For these family carers, embracing the need to be more adaptive brought positive redefinitions of self and relationships within the family group. As a result, Relational Social Engagement (RSE) during family interactions was something to be enjoyed despite the distress of loss and uncertainty. For health professionals, RSE offers opportunities to optimise wellbeing and psychological growth in family members, despite changing relational and social connections in dementia.

\section{Acknowledgments}

Our thanks go to the families who gave generously of their time in sharing their dementia narrative.

\section{Author Contributions}

The first author recruited the participants, collected, and transcribed the data sets. The first author and second author jointly developed the design, were independent auditors and coauthors.

\section{Funding}

No funding was received for this research study.

\section{Competing Interests}

The authors have declared that no competing interests exist.

\section{Appendix}

Notations:

- Indicates a pause in speech.

... Indicates removal of nonessential material.

\section{References}

1. Boss P. The trauma and complicated grief of ambiguous loss. Pastoral Psychol. 2010; 59: 137145.

2. Mccormack L, Tillock K, Walmsley BD. Holding on while letting go: Trauma and growth on the pathway of dementia care in families. Aging Ment Health. 2017; 21: 658-667. 
3. Walmsley BD, Mccormack L. Shame, hope, intimacy and growth: Dementia distress and growth in families from the perspective of senior aged care professionals. Dementia. 2016; 15: 1666-1684.

4. Walmsley BD, Mccormack L. Synthesis of meaning: Negative and positive change in family members following the adversity of dementia. J Humanistic Psychol. 2016; 56: 122-143.

5. Santulli RB, Blandin K. The Emotional Journey of the Alzheimer's Family: Dartmouth College Press; 2015.

6. Figley CR, Bride BE, Mazza N. The traumatology of grieving. Philadelphia, PA: Brunner/Mazel; 1998.

7. Allan K, Killick J. Communicating with people with dementia. In J. C. Hughes, M. LloydWilliams, \& G. A. Sachs. (Eds.), Supportive care support for the person with dementia, Oxford: Oxford University Press. 2010.

8. Harré R. Personal Being. Oxford: Blackwell. 1983.

9. Harré R. The discursive production of selves. Theory Psychol. 1991; 1: 51-63.

10. Sabat SR, Collins M. Intact social, cognitive ability, and selfhood: A case study of Alzheimer' s disease. Ageing Soc. 1999; 12: 443-461.

11. Phillipson L, Magee C, Jones SC, Reis S, Skladzien E. Exploring dementia and stigma beliefs. A pilot study of Australian adults 40 to 65 years. Alzheimer's Australia Canberra Australia; 2012.

12. Sachs GA, Shega JW, Cox-Hayley D. Barriers to excellent end-of-life care for patients with dementia. J Gen Intern Med. 2004; 19: 1057-1063.

13. Tabak N, Ehrenfeld M, Alpert R. Feelings of anger among caregivers of patients with Alzheimer's disease. Int J Nurs Prac. 1997; 3: 84-88.

14. Snyder M, Egan EC, Burns KR. Efficacy of hand massage in decreasing agitation behaviors associated with care activities in persons with dementia. Geriatr Nurs. 1995; 16: 60-63.

15. Bryden C. Dancing with dementia : My story of living positively with dementia. London: Jessica Kingsley Publishers; 2005.

16. Peterson RC. Mild cognitive impairment as a diagnostic entity. J Int Med. 2004; 256: 183-194.

17. Taylor R. Alzheimer's from the inside out. Baltimore, MD: Health Professions Press. 2007.

18. Walmsley BD, Mccormack L. Moderate dementia: Relational social engagement (RSE) during family visits. Aging Ment Health. 2017.

19. Walmsley BD, Mccormack L. Severe dementia: Retained social engagement (RSE) during family visits.(In press). Aging Ment Health. 2016.

20. Dennett DC. The intentional stance. Cambridge, Massachusetts, USA: MIT Press; 1987.

21. Rogers CR. Empathic: An unappreciated way of being. Counseling Psychol. 1975; 5: 2-10.

22. Fazio S. The enduring self in people with Alzheimer's: Getting to the heart of individualized care. Baltimore: Health Professions Press; 2008.

23. Walmsley BD, Mccormack L. The dance of communication: retaining family membership despite severe non-speech dementia. Dementia. 2014; 13: 626-641.

24. Shuter $\mathrm{P}$, Beattie $E$, Edwards $\mathrm{H}$. An exploratory study of grief and health-related quality of life for caregivers of people with dementia. Am J Alzheimers Dis Other Dement. 2013; 29: 379385.

25. Figley C. Compassion Fatigue. Coping with secondary traumatic stress disorder in those who treat the traumatized. Florence: Brunner/Mazel; 1995. 
26. Joseph S. What doesn't kill us: The new psychology of posttraumatic growth. New York: Basic Books; 2011.

27. Joseph S, Linley PA. Trauma, recovery, and growth: Positive psychological perspectives on posttraumatic stress. New Jersey: John Wiley \& Sons; 2008.

28. Janoff-Bulman R. Shattered assumptions: Towards a new psychology of trauma. New York: Free Press; 1992.

29. Joseph S, Linley PA. Positive adjustment to threatening events: An organismic valuing theory of growth through adversity. Rev Gen Psychol. 2005; 9: 262-280.

30. Lepore S, Revenson TA. Resilience and posttraumatic growth: Recovery, resistance, and reconfiguration. In L. G. Calhoun, \& R. G. Tedeschi. (Eds.), Handbook of posttraumatic growth: Research and practice. Mahwah, New Jersey, USA: Lawrence Erlbaum; 2006.

31. O'Leary VE, Ickovics JR. Resilience and thriving in response to challenge: An opportunity for a paradigm shift in women's health. Womens Health. 1995; 1: 121-142.

32. Smith BW, Dalen J, Wiggins K, Tooley E, Christopher P, Bernard J. The brief resilience scale: assessing the ability to bounce back. Int J Behav Med. 2008; 15: 194-200.

33. Ryan RM, Deci EL. Self-determination theory and the facilitation of intrinsic motivation, social development, and wellbeing. Am Psychol. 2000; 55: 68-78.

34. Folkman S, Maskowitz J. Positive psychological states and coping with severe stress. Soc Sci Med. 1997; 45: 1207-1221.

35. Kramer BJ. Differential predictors of strain and gain among husbands caring for wives with dementia. Gerontologist. 1997; 37: 239-249.

36. Lawton MP, Moss M, Kleban MH, Glicksman A, Rovine M. A two-factor model of caregiving appraisal and psychological well-being. J Gerontol. 1991; 46: 181-189.

37. Gadamer H. Hermeneutics as practical philosophy. In F. G. Lawrence (Trans.), Reason in the age of science(pp. 88-138). Cambridge: The MIT Press; 1983.

38. Mead GH. Mind, self and society. Chicago: University of Chicago Press; 1934.

39. Ashworth P. Psychology and 'human nature'. Hove, UK: Psychology Press; 2000.

40. Morris JC. The clinical dementia rating (CDR): Current version and scoring rules. Neurology. 1993; 43: 2412-2414.

41. Smith JA. Beyond the divide between cognition and discourse: Using interpretative phenomenological analysis in health psychology. Psychol Health. 1996; 11: 261-271.

42. Palmer $M$, Larkin $M$, De Visser Rd, Fadden G. Developing an interpretative phenomenological approach to focus group data. Qual Res Psychol. 2010; 7: 99-121.

43. Smith JA. Reflecting on the development of interpretative phenomenological analysis and its contribution to qualitative research in psychology. Qual Res Psychol. 2004; 1: 39-54.

44. Smith J, Flowers P, Larkin M. Interpretative phenomenological analysis: Theory, methods and research. London: Sage; 2009.

45. Brocki JM, Wearden AJ. A critical evaluation of the use of interpretative phenomenological analysis (IPA) in health psychology. Psychol Health. 2006; 21: 87-88.

46. Larkin $M$, Watts $S$, Clifton E. Giving voice and making sense in interpretative phenomenological analysis. Qual Res Psychol. 2006; 3: 102-120.

47. Willig C. Introducing qualitative research in psychology: Adventures in theory and method. (3rd ed.). Berkshire, UK: McGraw-Hill Professional Publishing; 2013. 
48. Mccormack L, Joseph S. PHENOMENA: A 9-step guide to avoiding pitfalls when doing interpretative phenomenological analysis (IPA)-IPA and the "Lived" experience of complex trauma. London: Sage Publications; 2018.

49. Heidegger M. Being and time. New York: Harper; 1927/1962.

50. Smith JA, Osborne M. Interpretive phenomenological analysis. In J. A. Smith (Ed.), qualitative psychology: A practical guide to research methods. (2nd ed.). London: Sage Publications; 2008.

51. Smith JA, Michie S, Stephenson M, Quarrell O. Risk perception and decision-making processes in candidates for genetic testing for huntington's disease: An interpretative phenomenological analysis. J Health Psychol. 2002; 7: 131-144.

52. Spencer L, Ritchie J. In pursuit of quality. In D. Harper, \& A. R. Thompson, (Ed.), Qualitative research methods in mental health and psychotherapy: A guide for students and practitioners (pp. 209-223). Chichester, UK: Wiley-Blackwell; 2012.

53. Yardley L. Demonstrating validity in qualitative psychology. In Smith, J. A. (Ed.), Qualitative psychology: A practical guide to research methods. (2nd ed.). London: Sage Publications; 2008.

54. Green G, Lakey L. Building dementia-friendly communities: A priority for everyone. Alzheimer's Society: London. 2013.

55. Skladzien E, Holdsworth K. Dementia-friendly societies: The way forward. A report for Alzheimer's Australia (Paper 31). Retrieved from http://www.fightdementia.org.au. 2013.

56. Bonanno GA, Brewin CR, Kaniasty K, La Greca AM. Weighing the costs of disaster: Consequences, risks, and resilience in individuals, families, \& communities. Psychol Sci Public Interest. 2010; 11: 1-49.

57. Kaniasty K, Norris FH. Longitudinal linkages between perceived social support and posttraumatic stress symptoms: Sequential roles of social causation and social selection. J Traumatic Stress. 2008; 21: 274-281.

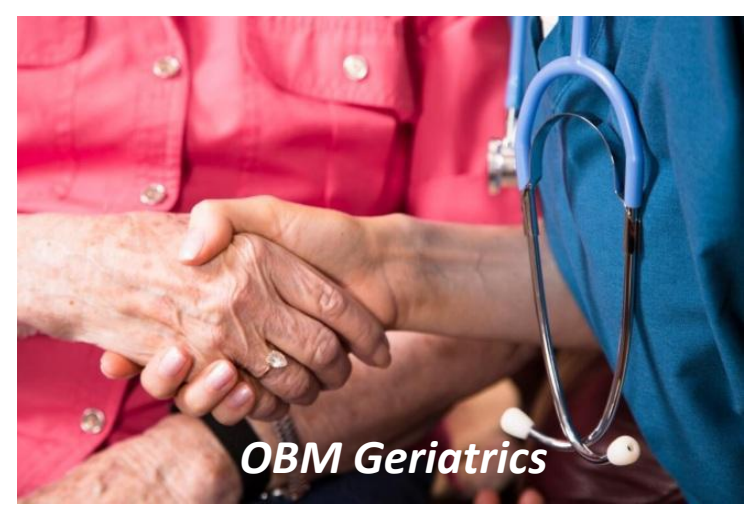

Enjoy OBM Geriatrics by:

1. Submitting a manuscript

2. Joining in volunteer reviewer bank

3. Joining Editorial Board

4. Guest editing a special issue

For more details, please visit: http://www.lidsen.com/journals/geriatrics 